\title{
Farmer's behaviors toward pesticides use: insight from a field study in Oriental Morocco
}

\author{
Jamal Benaboud*1, Mostafa Elachour ${ }^{2}$, Jamal Oujidi ${ }^{3}$, and Abdelhafid Chafi ${ }^{1}$ \\ ${ }^{1}$ University Mohammed I Sciences Faculty, Department of Biology Laboratory of Environment Oujda Morocco. \\ ${ }^{2}$ University Mohammed I Sciences Faculty, Department of Biology Laboratory of Ethnopharmacology Oujda Morocco. \\ ${ }^{3}$ Municipal Office of Public Health, Berkane Morocco. \\ *Correspondence: jamalbenaboud@yahoo.fr
}

Received: April 29, 2020 Accepted: November 05, 2020

\begin{abstract}
Pesticides are a vital component of modern agriculture. So, these chemical compounds could play a crucial role in maintaining high agricultural productivity. However, high-input intensive agricultural production systems in which more effective and widespread use of pesticides could harm human health and the environment. As we know, most of the farmers in developing countries used pesticides without taking the necessary precautions. The present study aims to assess farmers' knowledge and understand the pattern of use of pesticides in Oriental Morocco. We based our approach on a standardized questionnaire with 140 farmers to evaluate their knowledge, attitude, and awareness about the pictograms used on pesticide labels. The results show that the farmer had a low level of education; only $14 \%$ were in university. More than $65 \%$ overuse pesticides and $60 \%$ did not respect the pre-harvest interval. Many farmers did not know the standard pictograms used on pesticide labels, $90 \%$ acknowledged only the crossbones and the fire sign, and $33 \%$ gave false interpretation or misunderstood these pictograms. These results show that the farmers in Eastern Morocco seem to be ignorant of pesticide danger and lack of safety education. They have no idea how to deal with the pictogram on the pesticide label. Pesticide safety education is necessary to induce protective behavior among farmers and prevent the residue of pesticides in foodstuff. The comprehension of pictograms on pesticide labels is crucial to reduce the risk of poisoning.
\end{abstract}

Keywords: Pesticides, Overuse, Knowledge, Pictograms

\section{Introduction}

Pesticides are widely used in agriculture to control a broad spectrum of devastating pests that spoil the crop [1] These chemicals are crucial for warranting economic development and food security and their unsafe and heavy use could be a significant threat to human and environmental health [2]. The statistics from the Food and Agriculture Organization (FAO) show that developing countries used about $30 \%$ of the pesticides in the world [4-7]. In this case, farmers are the first exposed to this kind of poisoning; the farmers are at a greater risk of pesticide exposure than others are[10]. Several studies confirmed these observations: the pesticides poison yearly more than 25 million farmers. Moreover, approximately three million farmers suffer from severe poisoning due to pesticides, particularly in the rural areas of developing countries [8].

Additionally, 180,000 deaths every year are registered [9]. We found in the literature that the first causes of this high incidence rate are the shortage of knowledge about the pesticides, low educational level, and insufficiency safety attitude, especially not using personal protective equipment by farmers before, during, and after pesticide application [1015]. Since 1988, the FAO, with the International Association of Agrochemical Manufacturers (Crop Life International), began promoting the pictogram to avoid contamination by pesticides [16, 17].

The FAO planned to implement the United Nations Globally Harmonized System for the Classification and Labeling of Chemicals (GHS) in 2008 [18]. The goal of the GHS was to use nine pictograms for communicating chemical hazards to encourage global recognition and prevention of potential environmental contamination and health hazard. These pictograms are a mechanism for communicating technical risk assessment data for specific pesticides in a perceived simple format, without words, and easy to understand universally by semi- and illiterate populations [18].

In Morocco, the adoption of the GHS had started in 2012 to become mandatory in 2015 [19] and the amount of pesticide used in Morocco is about 17,000 tons every year [19]. The agricultural sector contributes to gross domestic product (GDP) by $17 \%$ [20] and this makes pesticides unavoidable. The organization of phytochemicals in Morocco started early by the Decree of 1922. Since 2010, the office of food security (ONSSA) is the establishment that controls the homologation of 
pesticides and their uses. However, government control and law enforcement are still weak, and Morocco's illiteracy is about $45 \%$ [21].

Furthermore, Oriental Morocco has the second highest joblessness rate in the country, up to 17\% [21] and the vicinity of the Algerian border makes Oriental Morocco a fertile place for smuggled products. All these facts explain our choice of area of study in Oriental Morocco to investigate the pattern of pesticide use and assess the farmers' knowledge about the pictograms on pesticide labels. Our study evaluated farmers' behavior and set an understanding of the current pictograms on the pesticide label in this scope.

\section{Materials and methods Study area}

The majority of agriculture within Eastern Morocco areas concentrates on the lower Moulouya irrigated perimeter, which extends on 160,000 ha of arable land, including irrigated 80,000 ha. The province of Berkane only contains 60,000 ha (red box) of arable land with irrigated 40,000 ha

\section{Study design}

Berkane is divided into nine communes and we took a random sample of 140 farmers from five communes: Laatamna, Madagh, Boughriba, Reggada, and Chouihia, Morocco. They were chosen because they contain the principal agricultural activity in the Province of Berkane. We began the query from August 2010 to June 2011 and it took us ninemonth and ten field trips to complete our investigation. Subjects gave their oral informed consent to participate in the study after hearing the explanation of his objective. It was a face-to-face query with $20 \mathrm{~min}$ to perform the interview. During each field trip, a technician from the ORMVAM (Office of Agriculture in the Lower Moulouya) was our guide to approach the farmers.

The questionnaire was designed in French, translated into Arabic (the mother tongue of the farmers), and administered onfarm in Arabic. We elaborated on the questionnaire by identifying information gathered from the existing literature on pesticide use, and we took the lead from the discussions with farmers and ORMVAM technicians. Some questions were open-ended and others were closed questions in a multiple-choice format so that respondents had to select only the appropriate answer(s) that they thought best described their opinion or attitude on a particular issue. Some questions demanded multiple answers. The questionnaire contained three main sections. The first section was designed to collect information on the farmers' characteristics, including age, educational level, farm size, and the phytosanitary product. The second included their level of satisfaction regarding the origin of pesticides used (approved or smuggled), the knowledge about the PHI (pre-harvest interval), and the overuse of pesticides regarding the manufacturer's dose prescript The third and the last section was dedicated to assessing their knowledge about the standard pictogram used in pesticides label by the manufacturer in Morocco. We analyzed the data obtained from the questionnaire using Statistical Package for Social Sciences (SPSS; Chicago, IL, USA) program, version 22. We tested the significance of the difference between categories by using the chi-square test $(\mathrm{X} 2)$. P values of less than 0.05 were accepted as statistically significant.

\section{Results}

\section{Demographic of study from farmers}

Age and level of education are measured using well-defined ordinal scale categories. Table 1 shows that the highest percentage of respondents (45\%) belonged to the $40-60$ age group, followed by $32.8 \%$ in the $20-40$ group. The smallest number of respondents $(22.2 \%)$ is in the above 60 -age group. Regarding educational level, about $26 \%$ of the sampling population was illiterate; people with less than six years in school and with more than six years in school followed with $26.4 \%$ and $22.1 \%$, respectively. Respondents with a high level of education account for only $14.3 \%$.

\section{The size of the farm and pesticides used}

The results show that we can distinguish three classes of farm: farms with less than 5 ha called small parcel; between 5 to 20 ha medium parcel; and with more than 20 ha oversized parcel. The majority of the parcel was under 20 ha and the small parcel represents 31\%, and the remaining 14\% was the oversized parcel with superficies up to 120 ha (Figure $1)$.

The farmers used the insecticide (95\%) the most, followed by the fungicide $(80 \%)$ and the herbicide $(60 \%)$. We must mention that one farmer may use more than one class of pesticides. They used mineral fertilizer by more than $98 \%$, and the manure was used only by $43 \%$. 
Table 1. Demographic of study from farmers

\begin{tabular}{|c|c|c|c|c|c|}
\hline \multirow{2}{*}{ Sex } & & Women & Men & Total & Frequency \\
\hline & & $1(1 \%)$ & $139(99 \%)$ & 140 & \\
\hline \multirow{4}{*}{ Age } & 20-40 years & 1 & 45 & 46 & $32.8 \%$ \\
\hline & $40-60$ years & - & 63 & 63 & $45.0 \%$ \\
\hline & $\geq 60$ years & - & 31 & 31 & $22.2 \%$ \\
\hline & Average age & 39 & 45 & 44 & \\
\hline \multirow{5}{*}{ Level of education } & Illiterate & 1 & 35 & 37 & $26.4 \%$ \\
\hline & $\begin{array}{l}\text { Less than 6years } \\
\text { in school }\end{array}$ & - & 31 & 31 & $22.1 \%$ \\
\hline & $\begin{array}{l}\text { More than } 6 \text { years } \\
\text { in school }\end{array}$ & - & 52 & 52 & $37.1 \%$ \\
\hline & University & - & 12 & 12 & $8.6 \%$ \\
\hline & $\begin{array}{c}\text { Specialists } \\
\text { (Technician engineer) }\end{array}$ & - & 8 & 8 & $5.7 \%$ \\
\hline
\end{tabular}

\section{SIZE(ha)}

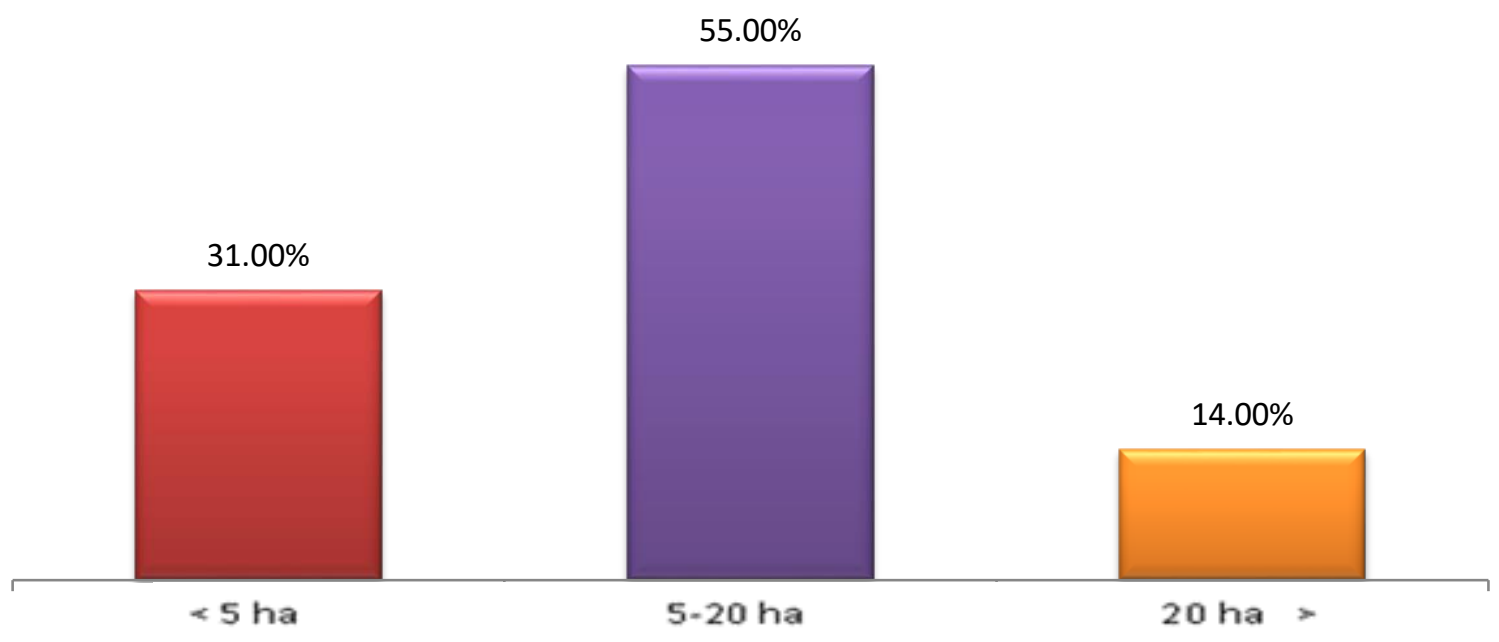

Figure 1. Size of the farm (ha)

\section{The satisfaction of users}

The smuggling activity is well known in the area of study because of the region's vicinity to the Morocco-Algerian frontier, so we asked the farmers if they are satisfied with the pesticides used. The level of satisfaction was on a scale of 1 to 3. The result shows that the farmers using approved pesticides were highly satisfied than those who use smuggled one (Table 2).

\section{Pesticides knowledge}

We found that most farmers do not respect the PHI: indeed, $60 \%$ of the farmers affirmed that they harvest their product (fruits, vegetables...) before the adequate time when they apply pesticides; only $40 \%$ of the farmers affirmed that they respect the PHI. More than $66 \%$ do not use the proper safety measure in terms of security of use and do not wear any protective cloth (glove, mask, shoes). More than $65 \%$ overuse pesticides effectively and they do not respect the manufacturer's dose. We conducted a Chi-squared test to assess the relationship between education and knowledge about pesticides. The illiterate people or the ones with lower educational levels show a shortage of experience about pesticides, and they do not take any preventive measure of security $\left(\mathrm{p}<10^{-5}\right)$. The farmer with a higher level of education, such as academic level or specialist (technician, engineer), are the most with good knowledge about those chemicals, and they took the correct measure of security when applying the pesticides $\left(\mathrm{p}<10^{-3}\right)$. 
Table 2. level of satisfaction of farmer

\begin{tabular}{cc}
\hline & $\begin{array}{c}\text { Rate of satisfaction } \\
\text { (on a scale of 1 to 3) }\end{array}$ \\
\hline Approved pesticides & 2.6 \\
\hline Smuggled pesticides & 1.4 \\
\hline
\end{tabular}

Table 3. Behavior of farmers with direct contact with pesticides.

\begin{tabular}{lcc}
\multicolumn{1}{c}{ Variable } & Total & Frequency \\
& $(\mathrm{n}=140)$ & $37.8 \%$ \\
\hline Respect the PHI (pre-harvest interval) & 53 & $62.2 \%$ \\
Yes & 87 & $7.1 \%$ \\
No & & $39.2 \%$ \\
Prevention measure & 10 & $55.7 \%$ \\
Wear special cloth & 55 & $71.4 \%$ \\
Wear a mask & 78 & $44.2 \%$ \\
Does not manipulate with bare hand & 100 & 62 \\
Does not eat during application & & $31.4 \%$ \\
Does not smoke during application & 44 & $68.6 \%$ \\
Respecting the dose prescribed & 96 & \\
Yes & & \\
No & & \\
\hline
\end{tabular}

\section{Comprehension of pictograms used on pesticides labels}

To understand how the label plays a role in farmworker's analysis of pesticide's potential risk, we asked them if they can identify the standard pictogram on the brands of pesticides (Figure 3). Indeed the skull and crossbones symbol and the flame label were by far the most frequently identified component. The oxidizer pictogram was the least identified by the farmers (Figure 4). Only 2\% acknowledged the corrosive label. However, 33\% gave a false interpretation of the pictograms, and $2.5 \%$ affirms they did not know any of the pictograms on pesticide labels. Moreover, the same as for the knowledge about pesticides, the farmers with better recognition of the pictograms were the ones who had a higher level of education $\left(p<10^{-4}\right)$, a low level of education was associate with making mistakes on the interpretation of those pictograms $\left(p<10^{-3}\right)$.

\section{Comparative analysis}

To assess the relationship between farmers' educational level and knowledge and the role of pictograms in danger perception. We conducted a correspondence analysis. The mapping of this correspondence shows a positive impact on the level of education on farmers' behavior. Indeed the high level of education was in conjunction with the good agricultural practice and in the same logic, the illiterate and the low education farmers were more likely not to follow the safety attitude when using pesticides.
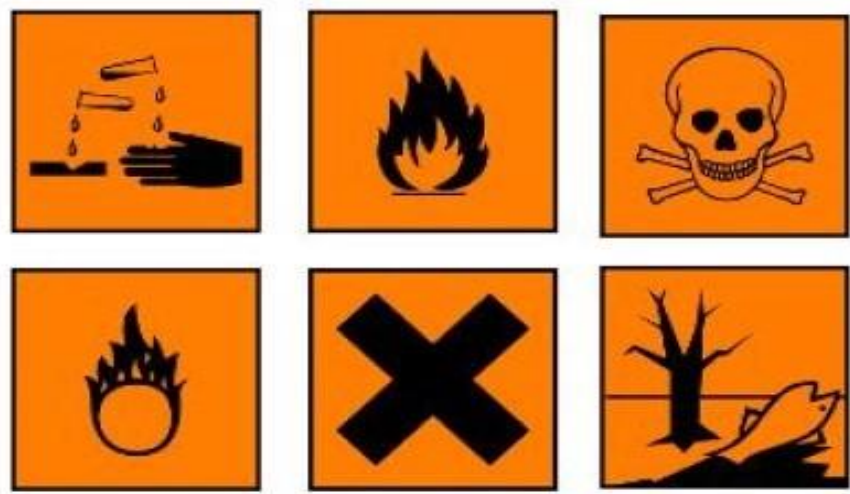

\section{1: Corrosive}

\section{2: Flammable}

3: Toxic

4: Oxidizer

5: Nocif

6: Harmful to the environment

Figure 2. Commons pictograms used on pesticides labels in Morocco 


\section{False response or interpretation}

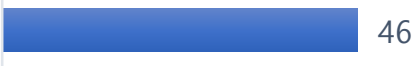

Corrosive 6

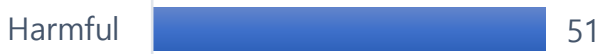

Toxic

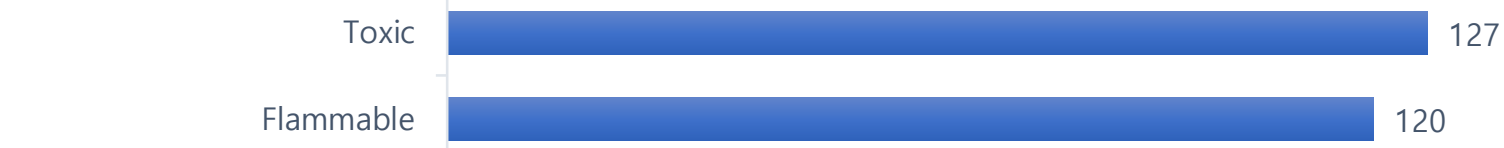

Flammable

\section{Oxidizer | 1 \\ Harmful to the environment \\ Non response 3}

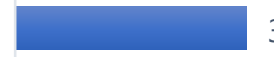

Figure 3. Pictograms knowledge of the farmers. $(n=140)$.

\section{Discussion}

Several studies supposed that farmers with increased perceptions of pesticides as hazards to human health and the environment would lower their use of pesticides [22-24]. The majority of farmers in the area of study considered pesticides a toxic product; That may have harmful effects on the environment and human health [25]. Still, this did not have a positive potency on their pesticide use in the opposite of expectations. It is plausible to state that most farmers in this survey do not give great weight to environmental and human health factors when applying pesticides. The study area is well known for using smuggled pesticides [26] and in our case, the farmers using the smuggled product are less satisfied with the result than the one who uses the approved one. These findings are not particularly surprising; the farmers' primary concern is to guarantee high yields and so for them, the overuse of pesticides or a low-cost smuggled product is the only way $[27,28]$.

More than half of the farmers in our study do not respect the PHI, which may hurt human health [29], and may occur to exceeding of the MRL (Maximum Residue Limit) in foodstuff $[29,30]$. Furthermore, the farmers used incorrect and high-risk methods for handling and applying pesticides. Their prevention measures are useless by knowing that if the applicator uses the protection equipment we can decrease the chance of poisoning by $44 \%$ [22].

The level of education was a determining factor. Indeed, the higher the level of education was, the better the knowledge of pesticides and the handling of this dangerous chemical were. Several studies in other developing countries showed the same result [31-33]. According to that, there is a pressing need for pesticide education as a risk communication tool. The primary objectives of education are to ensure that farmers understand pesticides' health hazards and adopt proper work practices. They must become familiar with protective measures, and use equipment properly, practice personal hygiene measures. For their safety, they must recognize early symptoms of overexposure or poisoning and obtain first aid at the most initial time possible; The World Health Organization (WHO) recommends using pesticides only by trained people [34, 35]. In Morocco, the manufacturer's standard pictograms do not play their role as intended. Besides, the labeling on pesticides does not give sensitive information on how to handle this phytosanitary product. Our work shows an essential percentage of the farmers do not recognize these pictograms, and they misunderstand almost a third of the subject. Furthermore, in the time we conduct, our investigation the pictograms used on the packing of pesticides were not the GHS. However, the success of the GHS to prevent the misuse of pesticides and lower the risk from these chemicals on the health has been controversial, especially in developing countries [36]. In South Africa, the farmworkers not only misunderstood the pictograms but also they often confuse interpretations, leading to inducing even riskier behaviors [37]. Pictograms are less likely to fall victim to misinterpretations if the target audience is involved in the process of developing these pictograms and are context-specific [39]. In some countries (e.g., the USA, Italy, and Japan), there are attempts to develop risk communication tools through a participatory process of engaging the target population in designing them [43-45].

Findings in our study will enable authorities to make more wise decisions and policy recommendations to prevent 
or reduce the threat of pesticides for health and the environment. They could also use the knowledge gaps identified in this study to design training programs for farmers more accurately. Participation in training programs leads to increased knowledge about safety precautions while handling pesticides [38,39]. Some developing countries, such as Nicaragua and Puerto Rico, undertake an action-oriented approach to farmworkers' education: teaching farm workers about the hazards and safe use of pesticides and empowering them to take preventive and protective actions gave a positive result [37]. In China, a safety education program decreased pesticide poisoning prevalence from $1.05 \%$ to $0.25 \%$ in one village taken as a leading experience [43]. The government must develop adequate training programs on pesticide safety, and the hazards of pesticide exposure must address gaps in farmers' knowledge. The extension service of the Ministry of Agriculture in Morocco should play a crucial role in the training of farmers, and the information they provide should be up-to-date, accurate, and easy to understand to inspire confidence and trust among the farmers. A trustworthy relationship with the informant may shape the perception of the risk of pesticides and the endorsement of preventive measures [40].

According to our result, the illiteracy rates (26\%) among farmers are high. They cannot write and read, and this is a challenge in designing appropriate training programs, for example, pictograms. They should be unambiguous and easy to understand to prevent misinterpretations of the risk information. Using pictograms is a critical element for overcoming literacy challenges in transmitting pesticide risk information [36]. Field demonstration can reinforce the knowledge of the farmers. Such capacity-enhancement activities will allow farmers to learn and understand how to handle pesticides safely and incrust in their behavior the preventative measures to minimize the risk from occupational exposure. It is also vital to train farmers about alternative cropping systems that are less dependent on pesticides and friendly to the environment while at the same time promoting integrated pest management practices. Ideally, the developing countries should adopt this process, especially with pesticide label development and farmers. In most developing countries, we can identify several significant obstacles to agrochemical safety. There is insufficient legislation for pesticide use and registration, in addition to a lack of regulatory research facilities to monitor pesticide residues and effects [35, 37].

Besides the farmers' training to reduce the risk of pesticides, the authorities must adopt other strategies - the enforcement of existing pesticide laws and regulations by monitoring the use of pesticides. The use of these chemicals must be only for trained people with a pesticide safety certification. It is also crucial to raise awareness about the risk of pesticides among the general public because exposure to harmful residues in foodstuff is the most common [45].

A limitation of this study is relying on the honesty of respondents. The query is based mainly on self-reported data, which is subjected to bias. As a self-report, there may be some inaccurate information, such as respondents wanting to report socially desirable behaviors. When we asked them if they wear protective gear when applying the pesticides or if they adopted other safety practices may be influenced by the respondents' desire to show that they adhere to the Good Agricultural Practices. Considering the number of farmers $(n=140)$, we cannot claim that our results represent all Moroccans Farmers. It's practically impossible to interview all farmers in Morroco. We aimed to explore and highlight pesticide safety issues for farmers, regardless of its limitation. This study provides an overview of pesticide safety knowledge and practices among farmers in Morocco and may play a part in educational and policy suggestions to prevent and reduce the hazards associated with pesticides.

\section{Conclusions}

Our study reveals a lack of adequate knowledge among farmers in Morocco and includes an insufficient use of protective equipment, the overuse of pesticides, and a misunderstanding of pictogram labels on pesticides. We recommend that the authorities prioritize developing and implementing educational pesticide safety and certification programs for farmers. This training must focus on the health and environmental effects of pesticides, improvements in the pictograms' clarity on pesticide labels, and understanding of the pesticide regulatory system in Morocco. Also, the use of the smuggled product is a real problem that must be severely restricted. Lastly, the Ministry of Agriculture's intervention strategies must tighten the enforcement mechanism of current pesticide laws, regular trough surveillance, and monitoring pesticide safety conformity at both retailer and farm levels to minimize the impact of the phytosanitary product on the environment and public health.

\section{Acknowledgement}

The authors wish to thank the study participants for their contribution to the research. The authors would specifically like to thank Dahmani Miloud, Azouzi Mohamed, and Boukheffa Driss; for their valuable help in the field investigation near the farmers.

\section{Conflict of interest}

None. 


\section{Author's Contributions}

The principal author's done this work for his thesis to obtain a Doctor grade, Dr.Oujidi gave valuable aid in the fieldwork, and the orientation, the directors of the thesis El Achouri and Chafi help with the elaboration of the manuscript and the analysis of the results.

\section{CRediT author statement}

JB: Conceptualization, Methodology, Software, Data curation, Writing- Original draft preparation, Visualization, Investigation, Supervision, Writing- Reviewing, and Editing; MEA: Conceptualization, Methodology, Software, Supervision, Writing- Reviewing, and Editing; JO: Visualization, Investigation; AC: Supervision, Writing- Reviewing, and Editing.

\section{References}

[1] M FernÁndez, Y PicÓ, J MaÑes. Pesticide residues in oranges from Valencia (Spain), Food Addit Contam 2001;18(7):615-624.

[2] Moser F, Dondi F. Environmental protection between chemical practice and applied ethics: a critical review. Toxicol Environ Chem 2015;98(9):1026-1042.

[3] Food and Agricultural Organization (FAO). FAOSTAT 2014 statistic on pesticides uses. [cited Dec 25, 2014]. Available from: http://www.fao.org/faostat/en/\#data/RP.

[4] Kishi, M. The health impacts of pesticides: what do we now know? In: Pretty J, editor. The Pesticide Detox: Towards a More Sustainable Agriculture. Earthscan;2005.

[5] Strong LL, Thompson B, Coronado GD, Griffith WC, Vigoren EM, Islas I. Health symptoms and exposure to organophosphate pesticides in farmworkers. Am J Ind Med 2004;4:599-606.

[6] Alvanja MCR, Hoppin JA, Kamel F. Health effects of chronic pesticide exposure: cancer and neurotoxicity. Annu Rev Public Health 2004;25:155-197.

[7] Kamel F, Hoppin JA. Association of pesticide exposure with neurologic dysfunction and disease. Environ Health Perspect 2004;112(9),950-958.

[8] Colosio C, Tiramani M, Maroni M. Neurobehavioral effects of pesticides: state of the art. Neurotoxicology 2003;24(4-5):577-591.

[9] Dalvie MA, Myers JE, Thompson ML, Dyer S, Robins TG, Omar S, et al. The hormonal effects of long-term DDT exposure on malaria vector-control workers in Limpopo Province, South Africa Environ Res 2004;96(1):9-19.

[10] Calvert GM, Karnik J, Mehler L, Beckman J, Morrissey B, Sievert J, et al. Acute pesticide poisoning among agricultural workers in the United States, 1998- 2005. Am J Ind Med 2008;51(12):883-898.

[11] Akter M, Fan L, Rahman MM, Geissen V, Ritsema CJ. Vegetable farmers' behaviour and knowledge related to pesticide use and related health problems: a case study from Bangladesh. J Clean Prod 2018;200:122-133.

[12] Fan L, Niu H, Yang X, Qin W, Bento CP, Ritsema CJ, Geissen V. Factors affecting farmers' behaviour in pesticide use: insights from a field study in northern China. Sci. Total Environ 2015;537:360-368.

[13] Okkofo ED, Mensah M, Fosu Mensah BY. Pesticides exposure and the use of personal protective equipment by cocoa farmers in Ghana. Environ Syst Res 2016;5(1):17-31

[14] Yarpuz-Bozdogan N. The importance of personal protective equipment in pesticide applications in agriculture. Curr Opin Environ Sci Health 2018;4:1-4.

[15] Sharifzadeh MS, Damalas CA, Abdollahzadeh G. Perceived usefulness of personal protective equipment in pesticide use predicts farmers' willingness to use it. Sci Total Environ. 2017;609:517-523.

[16] Goodman T. Impact of pesticide use on health in developing countries. In: Forget G, Goodman T, de Villiers A, editors. Proceedings of a Symposium held in Ottawa, Canada, 17-20 September 1990. International Development Research Centre; 1993. 
[17] Food and Agricultural Organization of the United Nations (FAO). International Code of Conduct on the Distribution and Use of Pesticides (Revised Version). FAO; 2002.

[18] Food and Agricultural Organization of the United Nations (FAO). International code of conduct on the distribution and use of pesticides-revised version. In: Adopted by the 123rd Session of the FAO Council in November 2002. FAO; 2005.

[19] Croplife Maroc. Article on the Moroccan market of pesticides [cited Mar 9, 2015 ]. Available from: http://www.croplife.ma/Pdf/Article_sur_le_marche_phytosanitaire_au_Maroc.mai_2011.pdf (French)

[20] The Ministry of Agriculture and Fishing (MAPM), Official statistics by the Ministry of Agriculture and Fishing. [cited Aug 20, 2014]. Available from: http://www.agriculture.gov.ma/en/node/220.

[21] The High Commission of the Plan (HCP) the official national census of 2 September 2014. [cited Mar 19, 2015]. Available from: https://www.hcp.ma/downloads/RGPH-2014_t17441.html. (French)

[22] Dasgupta S, Meisner C, Wheeler D, Xuyen K, Lam NT. Pesticide poisoning of farm workers-implications of blood test results from Vietnam. Int J Hyg Environ Health 2007;210(2):121-132.

[23] Hashemi SM, Rostami R, Hashemi MK, Damalas CA. Pesticide use and risk perceptions among farmers in southwest Iran. Hum Ecol Risk Assess 2012;18(2):456-470.

[24] Liu EM, Huang J. Risk preferences and pesticide use by cotton farmers in China. J Dev Econ 2013;103:202-215.

[25] Benaboud J, Oujidi J, Elachouri M, Chafi A. Quantification of Current use and Management of Pesticides by Farmers in Oriental Morocco: The Case of Berkane District, Morocco. Int Res J Earth Sci 2015;3(3):4-8.

[26] Damalas CA, Georgiou EB, Theodorou MG. Pesticide use and safety practices among Greek tobacco farmers: a survey. Int J Environ Health Res 2006;16:339-348.

[27] Al-Zadjali S, Morse S, Chenoweth J, Deadman M. Factors determining pesticide use practices by farmers in the Sultanate of Oman. Sci Total Environ 2014;476-477:505-512.

[28] Benaboud J, Oujidi J, Elachouri M, Chafi A. Pesticides used by Moroccan's farmer in oriental Morocco: Case of Berkane region. Acad J Environ Sci 2014;2(4):052-058.

[29] Cengiz MF, Certel M, Goçmen H. Residue contents of DDVP (Dichlorvos) and diazinon applied on cucumbers grown in greenhouses and their reduction by duration of a pre-harvest interval and post-harvest culinary applications. Food Chem 2006;98(1):127-135.

[30] Salghi R, Zrouali H, Zougagh M, Bazzi L, Chakirand A, Rios A. Disappearance of Chlorpyrifos Ethyl Pesticide Residues on Tomatoes, Citrus Fruits and Sugar Beet Grown in the Open Field. Arabian J Chem 2008;1(3):219-226.

[31] Yassin MM, Abu Mourad TA, Saffi JM. Knowledge, attitude, practice, and toxicity symptoms associated with pesticide use among farm workers in the Gaza Strip. Occup Environ Med 2002;59(6):387-393.

[32] Salameh PR, Baldi I, Brochard P, Abi Saleh B. Pesticides in Lebanon : Knowledge Attitude and Practice study. Environ Res 2004;94(1):1-6.

[33] Yilmaz H. Analysis in terms of environmental awareness of farmers' decisions and attitudes in pesticide use: the case of Turkey. Bulg Chem Commun 2015;47:771-775.

[34] Dasgupta S, Meisne C, Huq M. A pinch or a pint? Evidence of pesticide overuse in Bangladesh. J Agric Econ 2007;58(1): 91-114.

[35] Kimani VN, Mwanthi MA. Agrochemicals exposure and health implications in Githunguri location, Kenya. East Afr Med J 1995;72(8):531-535.

[36] Rother HA. South African farm workers' interpretation of risk assessment data expressed as pictograms on pesticide labels. Environ Res 2008 108(3):419-427.

[37] Chen S, He F, Zhang Z, Gao Y, Zhou A, Xie C, et al. Evaluation of a safety educational program for the prevention of pesticide poisoning. Med Lav 1998;89(Suppl. 2):91-98. 
[38] Jones E, Mabota A, Larson DW. Farmers' knowledge of health risks and protective gear associated with pesticide use on cotton in Mozambique. J Dev Areas 2009;42(2):267-282.

[39] Chen S, He F, Zhang Z, Gao Y, Zhou A, Xie C, et al. Evaluation of a safety educational programme for the prevention of pesticide poisoning. Med Lav 1998;89:91-98.

[40] Rios-Gonzalez A, Jansen K, Sanchez-Perez HJ. Pesticide risk perceptions and the differences between farmers and extensionists: Towards a knowledge-in-context model. Environ Res 2013;124:43-53.

[41] Christopher S., Smith A., McCormick AKHG. Participatory development of a cervical health brochure for Apsaalooke women. J Cancer Educ 2005;20(3):173-176.

[42] Quandt SA, Doran AM, Rao P, Hoppin JA, Snively BM, Arcury TA. Reporting pesticide assessment results to farmworker families: development, implementation, and evaluation of a risk communication strategy. Environ Health Perspect 2004;112(5):636-642.

[43] Fukuzono T, Sato T, Takeuchi Y, Takao K, Shimokawa S, Suzuki I, et al. Participatory flood risk communication support system (Pafrics). In: Ikeda S, Fukuzono T, Sato T, editors. A Better Integrated Management of Disaster Risks: Toward Resilient Society to Emerging Disaster Risks in Mega-Cities. TERRAPUB and NIED;2006:191-211.

[44] Mereu A, Sardu C, Minerba L, Sotgiu A, Contu P. Participative risk communication in an industrial village in Sardina. J Epidemiol Community Health 2007;61(2):122-127.

[45] Jaga K, Dharmani C. Sources of exposure to and public health implications of organophosphate pesticides. Pan Am J Public Health 2003;14:171-185. 